\title{
Insulin-Binding Antibody: Reaction Differences with Bovine and Porcine Insulins
}

\author{
A. B. Kurtz, J. A. Matthews, and J. D. N. Nabarro \\ Cobbold Laboratories and Department of Nuclear Medicine, Thorn Institute of Clinical Science, The Middlesex Hospital Medical School, \\ London, England
}

Summary. Insulin treated patients frequently develop insulin-binding antibody. Antisera from some patients, treated with bovine or bovine/porcine insulin mixtures, react differently with bovine and porcine insulin while for others there is no difference: when there is a difference there is greater avidity for bovine than porcine insulin. We studied antisera from 16 patients who had previously been treated with bovine insulin and then were changed to porcine insulin. Dissociation rate constants and association rates were measured with bovine and porcine insulin. Significant differences were found in association rates, which correlated well with binding at equilibrium $(r=0.91)$, but not in dissociation rates. For 11 subjects who stayed on highly purified porcine insulin, long term reduction in insulin requirement correlated with the magnitude of the difference in antibody reaction to bovine and porcine insulin ( $\mathrm{r}=$ 0.74).

Key words: Insulin-binding antibody, bovine insulin, porcine insulin, association rate, dissociation rate.

Antibodies to insulin frequently occur in insulintreated patients and insulins from different animal species may react differently with these antisera. In 1944 Lowell [1] described a patient whose serum bound human insulin much less avidly than bovine/ porcine insulin as judged by insulin sensitivity and insulin neutralisation in bioassay. Berson and Yalow [2] described species differences using equilibrium studies. The specificity of insulin-binding antibody has often been considered to be the cause of alterations in insulin sensitivity when patients have been changed from one species of insulin to another [3-6]
- the usual pattern being an increase in sensitivity on changing from bovine to porcine insulin. An invitro test has been used to predict the change in insulin requirement with change of insulin species [4].

Since porcine insulins of high purity have been introduced for clinical use, there has been concern over alterations in insulin-dose requirements when patients are changed from conventional, less pure, insulins to highly purified insulins [6-7]. Insulin requirements may fall abruptly [6] or gradually [8-10] on change-over as a result of a change in insulin species as well as insulin purity.

Previous studies of insulin-binding antisera have been at equilibrium. Insulin activity in-vivo is a disequilibrium process and is governed by, amongst other things, the rate of association of insulin and antibody and the dissociation rate of antibody-bound insulin [11]. For this reason we have measured the association and dissociation rates of labelled bovine and porcine insulin with antisera.

\section{Materials and Methods}

Blood samples were collected at routine diabetic clinic visits and the plasma stored deep-frozen until studied.

Highly purified bovine and porcine insulins (provided by Nordisk Insulin Ltd.) were labelled with ${ }^{125}$ Iodine by means of Chloramine-T and purified on carboxymethyl cellulose (Whatman CF11) and Sephadex G100 columns [12]. The specific activities were $50-150 \mu \mathrm{Ci} / \mu \mathrm{g}$.

For insulin binding measurement $0.05 \mathrm{ml}$ of plasma was incubated for 24 hours at $4^{\circ} \mathrm{C}$ with $0.2 \mathrm{ml}$ of $0.1 \mathrm{~mol} / \mathrm{l}$ borate buffer, pH 8.3, containing bovine serum albumin $5 \mathrm{~g} / 1$ and $1-2 \mu \mathrm{U}$ of labelled insulin. Separation of bound from free ligand was with polyethylene glycol at a final concentration of $12.5 \% \mathrm{w} / \mathrm{v}$.

'Insulin binding capacity' (IBC) was assessed by a modification of Andersen's method [9, 13]: this expresses an antiserum's potency in terms of a standardised guinea pig antiserum which reacts equally with bovine and porcine insulin. 


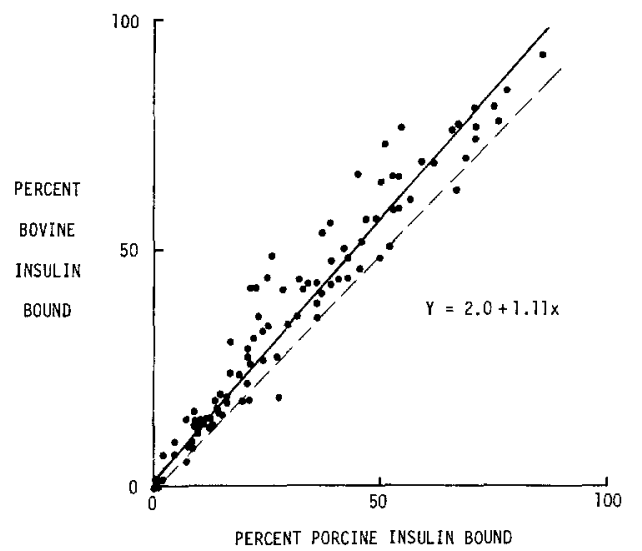

Fig. 1. The correlation of bovine and porcine insulin binding by sera from 98 patients treated either with bovine or bovine/porcine insulin. The solid line is the regression line, the dashed line is the line of equality and the correlation coefficient $r=0.92$

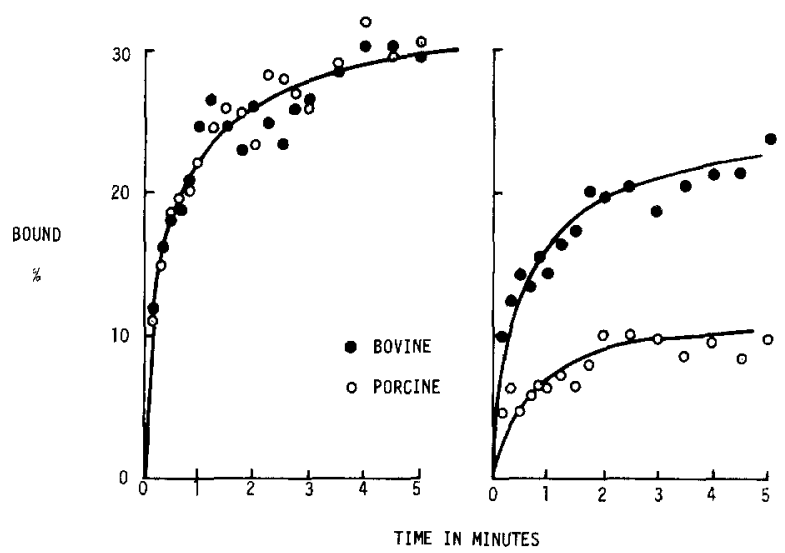

Fig. 2. Studies of the association rate of bovine and porcine insulin with antisera from two patients

Table 1. Summary of data for 16 patients treated initially with bovine and then with highly purified porcine insulin. Mean values are given with the standard errors. $\mathrm{P}$ was estimated by the paired $\mathrm{t}$-test

\begin{tabular}{lccccc}
\hline \multicolumn{5}{c}{ Bovine } & Porcine \\
\hline Insulin binding (\%) & 51.1 & \pm 3.1 & 44.0 & \pm 3.1 & $\mathrm{P}<0.0001$ \\
'Insulin binding capacity' IBC (mU/L) & 11.5 & \pm 20.9 & 88.5 & \pm 14.5 & $\mathrm{P}<0.02$ \\
Association rate (\%/min) & 21.2 & \pm 3.1 & 16.5 & \pm 2.6 & $\mathrm{P}<0.01$ \\
Dissociation rate constants $\left(\mathrm{Min}^{-1}\right)$ & & & $0.135 \pm 0.010$ & NS \\
k-1 & 0.148 & \pm 0.011 & $0.00492 \pm 0.0004$ & NS \\
k-2 & $0.00487 \pm 0.0005$ & & \\
\hline
\end{tabular}

For association rate determination [14] $0.1 \mathrm{ml}$ of plasma was incubated at $37^{\circ} \mathrm{C}$ with $20-40 \mu \mathrm{U}$ of labelled insulin in $0.5 \mathrm{ml}$ of $0.1 \mathrm{~mol} / \mathrm{l}$ borate buffer, $\mathrm{pH} 8.3$, with bovine serum albumin $5 \mathrm{~g} / 1$. At times varying from 10 seconds to 10 minutes after mixing, $0.025 \mathrm{ml}$ samples were taken and added to tubes containing $1 \mathrm{ml}$ of borate buffer with polyethylene glycol $15 \%$, bovine serum albu$\min 0.5 \mathrm{~g} / 1$, bovine gamma globulin $1.5 \mathrm{~g} / 1$ and $60 \mathrm{mU}$ of bovine insulin. These tubes were kept on ice until separated by centrifugation at $4^{\circ} \mathrm{C}$.

Dissociation $[11,14]$ was studied at $37^{\circ} \mathrm{C}$ by incubating $0.2 \mathrm{ml}$ of plasma with $0.2 \mathrm{ml}$ of borate buffer containing $40-80 \mu \mathrm{U}$ of labelled insulin. After 2 hours the incubate was added to $5 \mathrm{ml}$ of borate buffer containing bovine serum albumin $5 \mathrm{~g} /$, bovine gamma globulin $1.5 \mathrm{~g} / 1$ and $300 \mathrm{mU}$ bovine insulin. At times from 2 minutes to 1 hour $0.15 \mathrm{ml}$ samples were taken and added to tubes containing $0.5 \mathrm{ml}$ of ice cold $16.7 \%$ polyethylene glycol in borate buffer, which were kept on ice until separated by centrifugation at $4^{\circ} \mathrm{C}$.

Association rates and dissociation rate constants were calculated by graphical analysis.

Statistical analyses used least squares linear regression, Student's paired t test and Spearman's rank correlation.

\section{Results}

The antisera from bovine or bovine/porcine insulintreated diabetics showed a wide range of insulin binding; Figure 1 shows the comparison for binding of bovine and porcine labelled insulin. Average bind- ing of bovine insulin was $37.3 \%$ and porcine insulin $31.5 \%$ - the difference being significant (for paired $\mathrm{t}$-test $\mathrm{n}=98, \mathrm{t}=9.11$ ). For those sera with greater avidity for bovine than porcine insulin the difference was reproducible, similarly those sera binding the insulins equally did so reproducibly (rank correlation $r=0.80, p<0.01$ ). A group of 13 patients who were thought only to have received highly purified insulin from the time of diagnosis of diabetes showed more equal binding of bovine (mean binding $29 \%$ ) and porcine $(28 \%)$ insulin (paired t-test, $t=0.62 \mathrm{NS}$ ). Three individuals bound more bovine than porcine insulin and inspection of their hospital records showed that they had, in fact, received conventional bovine soluble insulin, for several days after diagnosis, before stabilization on the highly purified porcine insulin. For the subjects who had never received any bovine insulin mean porcine insulin binding $(27.7 \%)$ slightly exceeded bovine binding $(25.6 \%)$.

Plasma samples from 16 subjects were more extensively studied: these patients had all originally been treated with bovine insulin and then changed to highly purified porcine insulin. As in the larger group treated with bovine insulin the differences of antibody reactivity with bovine and porcine insulins 
covered a wide spectrum: the ratio of the response with bovine insulin to the response with porcine insulin ranged, for individuals, from 0.97 to 1.41 for insulin binding; from 0.51 to 1.89 for 'Insulin binding capacity' (IBC) and from 0.78 to 3.57 for association rate. For the whole group the mean bovine insulin binding exceeded porcine by $16 \%$, (paired t-test, $t=$ $4.0, \mathrm{p}<0.001$ ), and the mean IBC with bovine labelled insulin exceeded the IBC with porcine labelled insulin by $27 \%$ (paired t-test, $\mathrm{t}=2.62, \mathrm{p}<0.02$ ). Association rates with bovine and porcine labelled insulin showed differences. Figure 2 shows studies in two subjects; one showed a big species difference, the other none. For the group as a whole the association rate for bovine insulin was $28 \%$ greater than for porcine. The range for bovine association rates was $4.7-46.8 \%$ per minute, and for porcine association rates $4.5-42.2 \%$ per minute. The differences were significant (paired t test, $t=3.36$ ). These results are summarised in Table 1.

Dissociation rate studies give rapid $(k-1)$ and slow (k-2) rate constants. For the group as a whole there were no significant differences between the dissociation rates of bovine and porcine labelled insulin: for individuals there were minor differences only, which were not statistically significant.

Individual antisera appear to show consistent species differences when judged by insulin binding, IBC, and association rate. Rank correlation of the species differences (using the ratio of the response with bovine insulin to the response with porcine insulin) between insulin binding and association rate was $\operatorname{good}(\mathrm{r}=0.91, \mathrm{p}<0.01)$ : Rank correlation of IBC and association rate species difference $(r=0.46$, $\mathrm{p}<0.05$ ) and IBC and insulin binding species differences $(r=0.39, p>0.05)$, were less significant.

Eleven of the 16 subjects continued on purified porcine insulin given twice daily. The treatment change-over was made on average one year before the antiserum studies. Comparison of the insulin dose immediately after change-over and at the time of the study shows a mean reduction in insulin dose (from 53 to $46 \mathrm{U} /$ day). Rank correlation of dose reduction with bovine/porcine association rate difference was significant $(\mathrm{r}=0.74, \mathrm{p}<0.01)$.

\section{Discussion}

Our study confirms previous reports of differences between the binding of bovine and porcine insulin by some human antisera. The difference appears to be in the rate of association between insulin and antibody and not in the rate of dissociation of bound insulin. Different association rates will alter insulin delivery to cells - the usual pattern of a lower association rate for porcine than for bovine insulin would fit the increased sensitivity in some patients changed from bovine to porcine insulin as the free insulin concentration would be higher and insulin delivery to cells would increase. As there are no marked species differences in dissociation rate constants the species difference in the association rate will also be reflected in the equilibrium constants $(\mathrm{K})$ as $\mathrm{K}$ equals the association rate constant divided by the dissociation rate constant.

Studies of insulin-binding antibody are complicated by the presence of sizeable quantities of bound insulin. The half-life of removal of bound insulin is so slow that discontinuing treatment with insulin is not practical and we have not, in fact, standardised the time-interval from the last insulin injection. Some of the circulating antibody is free and some bound to insulin. The equilibrium between added labelled insulin and antibody-bound insulin is attained slowly and is clearly not reached in the measurements of association rate and dissociation rate; it is probably not reached in the $16 \mathrm{~h}$ incubation used for assessment of insulin binding but may be reached in the longer IBC assay. All of these methods really measure different dimensions of the insulin-binding antibody population. In a sense the association rate is the dimension closest to the in-vivo situation as it represents what happens as each increment of insulin enters the circulation: it correlates well, from the point of view of species differences, with insulin binding.

This study suggests that simple screening, by measuring insulin binding with bovine and porcine insulin, will detect patients at risk of increased insulin sensitivity when a change of insulin therapy is planned.

The clinical data presented here is limited and retrospective but suggests that reduction in insulin dosage over the long-term may also be a function of insulin-antibody specificity as well as the insulin purity and immunogenicity $[8,10]$. We also find that minimal exposure to bovine insulin, as was the case for the subjects who received bovine insulin for several days before long-term treatment with highly purified porcine insulin was started, can alter the pattern of antibody specificity: long term treatment with porcine insulin alone has however been reported, in a few subjects, to produce antibodies with greater avidity for bovine than porcine insulin as judged by IBC [15].

Further studies will require a comparison of insulin sensitivity with plasma free insulin levels after the administration of bovine and porcine insulin and a prospective study of insulin requirements in patient 
groups with different species reactivity on changeover to highly purified insulins.

Acknowledgements. We are grateful to Dr. J. D. Baum, Department of Paediatrics, John Radcliffe Hospital, Oxford, for allowing us to study sera from his patients.

\section{References}

1. Lowell, F. C.: Immunological studies in insulin resistance. J. Clin. Invest. 23, 225-240 (1944)

2. Berson, S. A., Yalow, R. S.: Species-specificity of human antibeef, pork insulin serum. J. Clin. Invest. 38, 2017-2025 (1959)

3. Boshell, B. R., Barrett, J. C., Wilensky, S., Patton, T. B.: Insulin resistance. Diabetes 13, 144-152 (1964)

4. Devlin, J. G., Brien, T. G.: Relationship between differential antibody binding capacity and clinical requirements of beef and pork insulin. Metabolism 14, 1034-1036 (1965)

5. de Mowbray, R. R.: Risk of changing from ox to pig insulin. Lancet 1966 II, 1027-1028

6. Asplin, C. M., Hartog, M.: Hazards of mono-component insulin. Br. Med. J. 1976 I, 1146

7. Logie, A.W., Stowers, J. M.: Hazards of monocomponent insulin. Br. Med. J. 1976 I, 879-880

8. Andreani, D., Lavicoli, M., Tamburrano, G., Menzinger, G.: Comparative trials with monocomponent (MC) and monospecies (MS) pork insulins in the treatment of diabetes mellitus. Horm. Metab. Res. 6, 447-454 (1974)

9. Mustaffa, B. E., Daggett, P. R., Nabarro, J. D. N.: Insulin binding capacity in patients changed from conventional to highly purified insulins. Diabetologia 13, 311-315 (1977)

10. Asplin, C. M., Hartog, M., Goldie, D. J.: Change of insulin dosage, circulating free and bound insulin and insulin antibodies on transferring diabetics from conventional to highly purified porcine insulin. Diabetologia 14, 99-105 (1978)

11. Kurtz, A. B., Mustaffa, B.E., Daggett, P. R., Nabarro, J. D. N.: Effect of insulin antibodies on free and total plasmainsulin. Lancet 1977 II, 56-58

12. Gavin, J. R., Roth, J., Jen, P., Freychet, P.: Insulin receptors in human circulating cells and fibroblasts. Proc. Natl. Acad. Sci. USA 69, 747-751 (1972)

13. Andersen, O. O., Brunfeldt, K., Abilgard, F.: A method for quantitative determination of insulin antibodies in human plasma. Acta Endocrinol. (Kbh.) 69, 195-208 (1972)

14. Berson, S. A., Yalow, R. S.: Quantitative aspects of the reaction between insulin and insulin-binding antibody. J. Clin. Invest. 38, 1996-2016 (1959)

15. Andersen, O. O.: Insulin antibody formation. Acta Endocrinol. (Kbh.) 72, 33-45 (1973)

Received: December 13, 1977,

and in revised form: February 27, 1978

Dr. A. B. Kurtz

Department of Nuclear Medicine

Thorn Institute of Clinical Science

The Middlesex Hospital Medical School

Mortimer Street

London W1N 8AA

England 